\title{
Exploring the need for Intellectual Property Information Literacy for Business and STEM disciplines
}

\author{
Janis Tyhurst \\ King Abdullah University of Science and Technology (KAUST), Thuwal, Saudi Arabia \\ Janis.tyhurst@kaust.edu.sa
}

\begin{abstract}
A major component of any information literacy training program incorporates training on copyright and fair use. While in the library literature, librarians have provided excellent training on understanding copyright and appropriate use, they have not focused on providing training on other forms of intellectual property (IP), particularly patents. As IP in the form of patents is becoming exponentially more important in the research-to-commercialization process, more work on information literacy training about patents is needed. This paper provides definitions of IP literacy, places the value of IP literacy in a larger context, looks at target audiences, proposes a framework for IP literacy and provides suggestions about the role that librarians can play in developing IP literacies beyond copyright.

Keywords. Information literacy, information training, intellectual property, intellectual property literacy.
\end{abstract}

\section{Introduction}

The emergence of freely available patent databases has opened up new opportunities for librarians to develop new skills and forge new collaborations. Intellectual property (IP) is vital to an innovative and growing economy, with the potential to stimulate employment and job growth as long as people are aware of and able to use IP effectively. Librarians can play an important role in supporting innovation and employment through the integration of IP literacy (IPL) training into their information literacy (IL) programs. Science, technology, engineering and mathematics (STEM) librarians, business librarians and arts librarians can be an important catalyst to spread IPL in their disciplines. Including IPL into academic IL programs enriches understanding that students of the discipline literature have about the role of IP in their studies and future employment. Developing IPL training also encourages collaboration across academic departments and demonstrates the value that librarians bring to the institution. Public Library librarians can use IPL as an opportunity to engage the local community, small-and-medium sized enterprises and entrepreneurs. This paper begins the discussion of IPL by providing definitions of IP literacy, demonstrating the value of IP literacy in a larger context, analyzing target audiences, proposing a framework for IP literacy and providing suggestions about the role that librarians can play in developing IP literacies beyond copyright.

\section{Definitions of Intellectual Property}

The following definitions of intellectual property (IP) are drawn from two major patent offices, the United States Patent and Trademark Office (USPTO) and the World Intellectual Property Office (WIPO).

The USPTO [1] defines IP as, "creations of the mind - creative works or ideas embodied in a form that can be shared or can enable others to recreate, emulate, or manufacture them. There are four ways to protect intellectual property patents, trademarks, copyrights or trade secrets." The WIPO [2, p.2] defines IP as, 
"creations of the mind, such as inventions; literary and artistic works; designs; and symbols, names and images used in commerce. Intellectual property is divided into two categories: Industrial Property includes patents for inventions, trademarks, industrial designs and geographical indications. Copyright covers literary works (such as novels, poems and plays), films, music, artistic works (e.g., drawings, paintings, photographs and sculptures) and architectural design. Rights related to copyright include those of performing artists in their performances, producers of phonograms in their recordings, and broadcasters in their radio and television programs."

\section{A Working Definition of Intellectual Property Literacy}

I propose to use the former American Library Association definition for IL [3] by substituting "intellectual property" for "information" and "intellectual property literacy" for "information literacy": Intellectual property literacy is a set of abilities requiring individuals to recognize when intellectual property is needed and to have the ability to locate, evaluate, and use effectively the needed intellectual property. An intellectual property literate individual is able to: determine the extent of intellectual property needed; access the needed intellectual property effectively and efficiently; evaluate intellectual property and its sources critically; incorporate selected intellectual property into one's knowledge base; use intellectual property effectively to accomplish a specific purpose; understand the economic, legal, and social issues surrounding the use of intellectual property; and access and use intellectual property ethically and legally.

\section{$4 \quad$ Reasons for Developing an IP Literacy Training Component}

To understand why developing IPL is important opportunity for librarians, we need to look first at the big picture of the value of IP to the economy. The USPTO report on IP and the U.S. economy [4] states that "IP-intensive industries continue to be a major, integral and growing part of the U.S. economy." This value is demonstrated by the increasing share of IP-intensive industries to the total US gross domestic product (GDP), which increased from 34.8 percent in 2010 to 38.2 percent in 2014 or from $\$ 5.06$ trillion to $\$ 6.6$ trillion. Figure 1 graphically shows the contributions of IP-related and non-IP-related economic activity to the US GDP in 2010. Figure 2 graphically shows the same contributions in in 2014. 


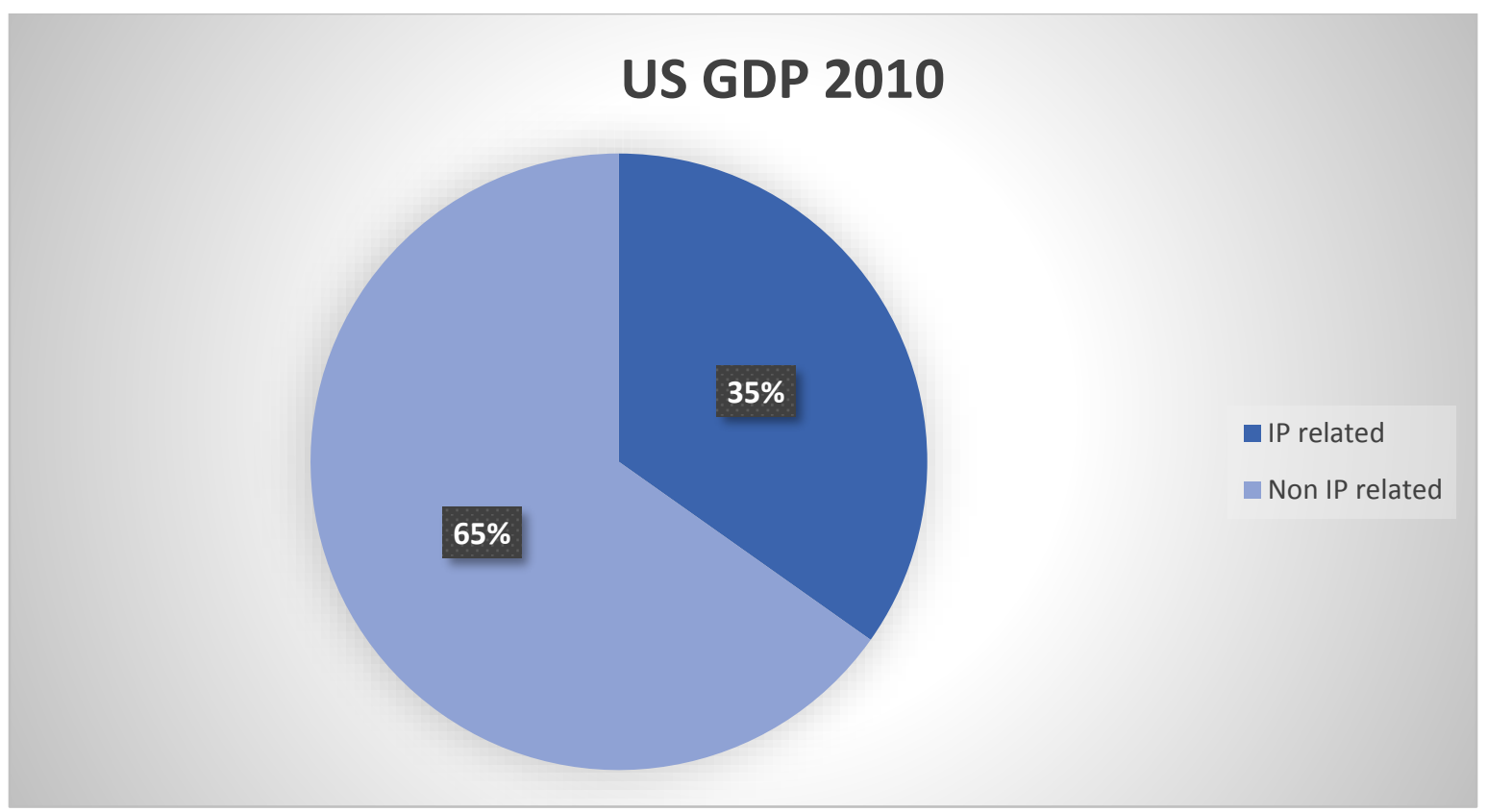

Fig. 1. Contribution of IP to the US GDP in 2010 (2016 USPTO report)

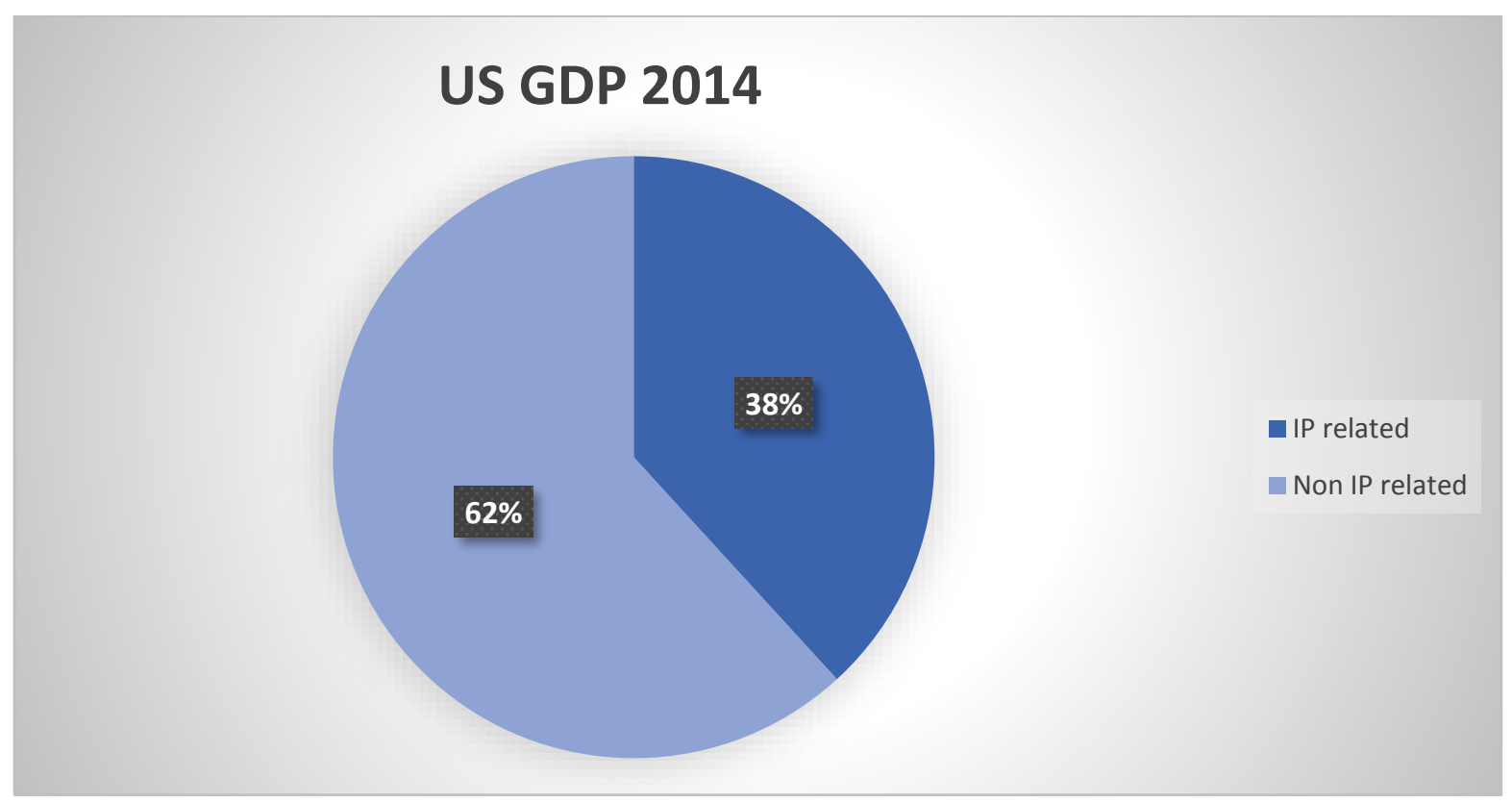

Fig. 2. Contribution of IP to the US GDP in 2014 (2016 USPTO report)

In addition, wages for IP-intensive industries are consistently higher than those for non-IP industries, with IP-related jobs earning a weekly average of $46 \%$ more than non-IP-related jobs. IP-intensive industries accounted for $30 \%$ of both direct and indirect employment in 2014, or 1 of every 3 jobs. Figure 3 shows the IP-related and non-IP-related average weekly wages in the US in 2014 and Figure 4 shows the proportions of IP-related and non-IP-related jobs in the US in 2014. 


\section{US Average Weekly Wages 2014}

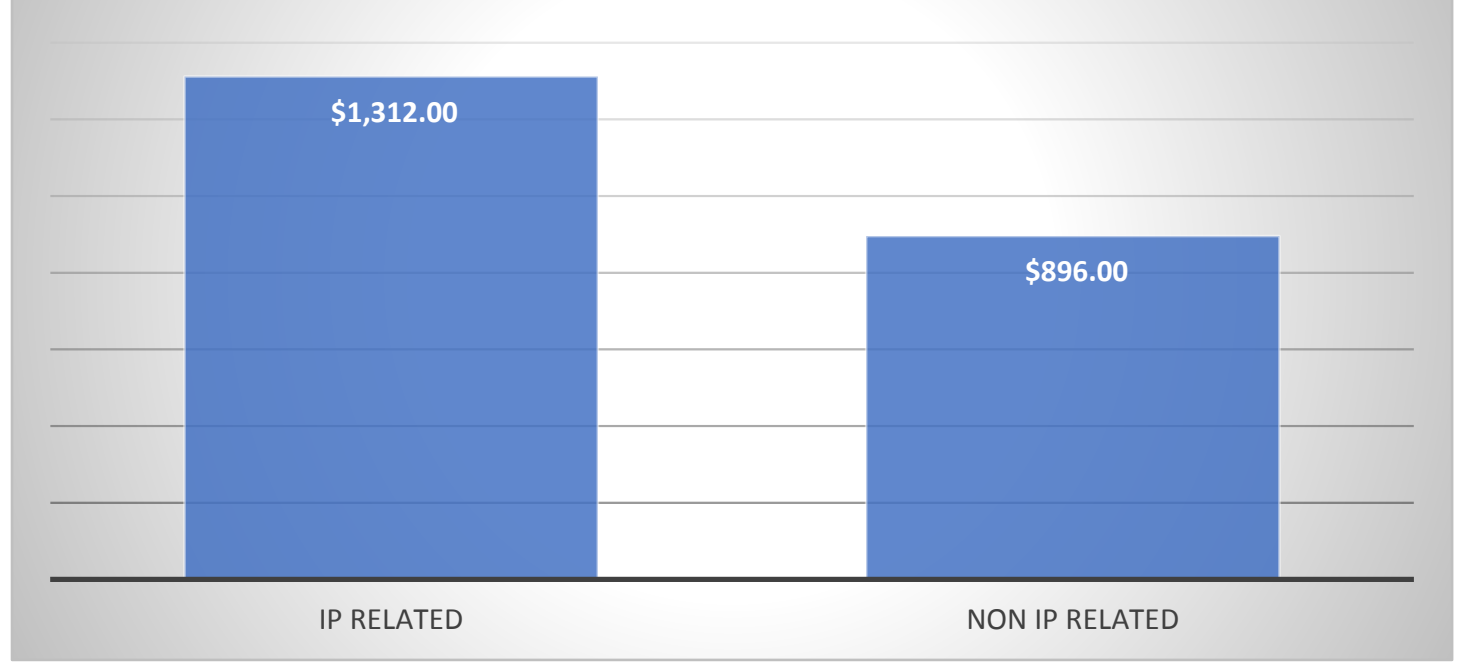

Fig. 3. Average weekly wages in the US in 2014 (2016 USPTO report)

\section{US Employment 2014}

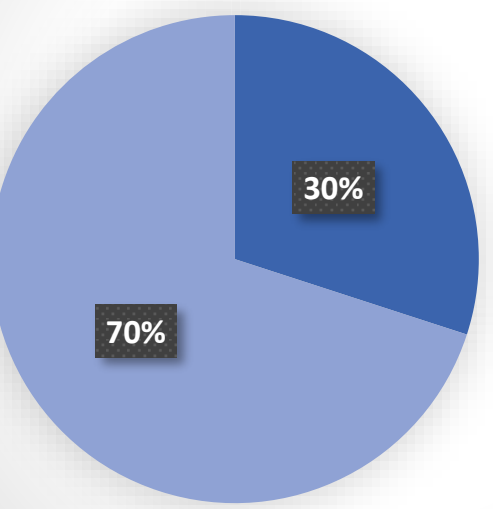

- IP related

Non IP related

Fig. 4. IP-related and non-IP-related employment in the US in 2014 (2016 USPTO report) The following three graphs from the European Union Intellectual Property Office (EUIPO) [5] show similar trends to those found in the US. The EUIPO graphs are further refined by type of IP. 


\section{Contribution of IPR-intensive industries to GDP}

$42 \%$ of total economic activity (GDP) in the European Union was generated by IPR-intensive industries during the period 2011-2013

This totals over $€ \mathbf{5 . 7}$ trillion annually
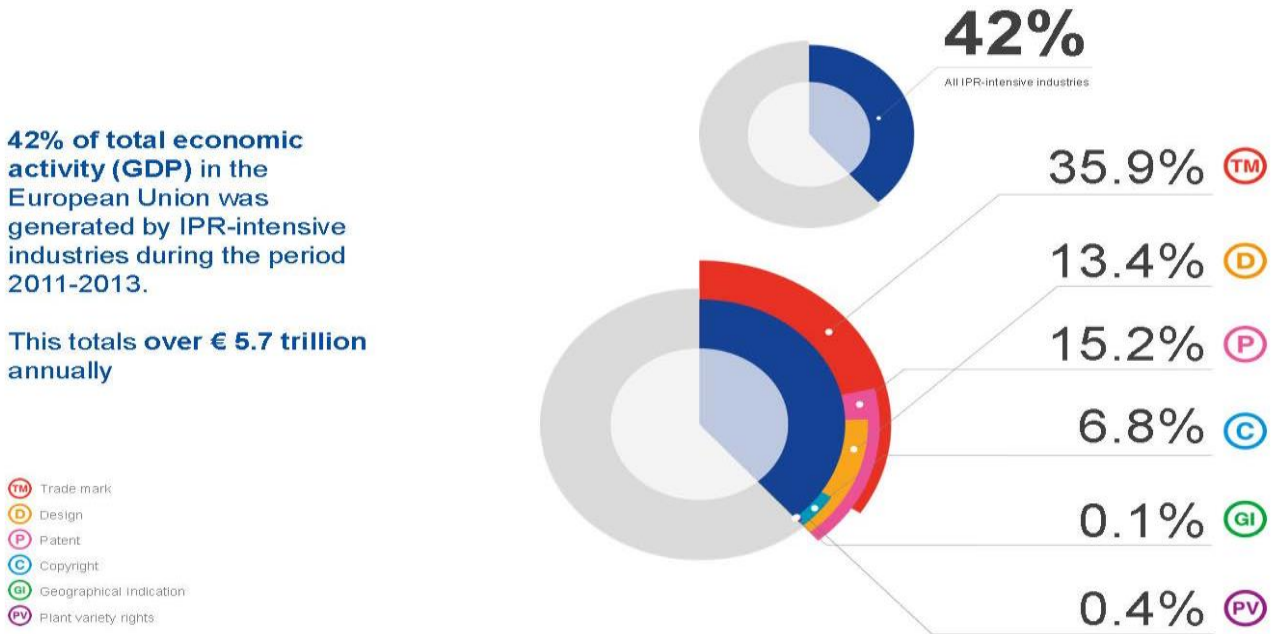

Fig. 5. IP-related employment in the EU in 2015 (EUIPO, Intellectual property rights intensive industries and economic performance in the EU)

Q EUIPO

\section{Contribution of IPR-intensive industries to employment}

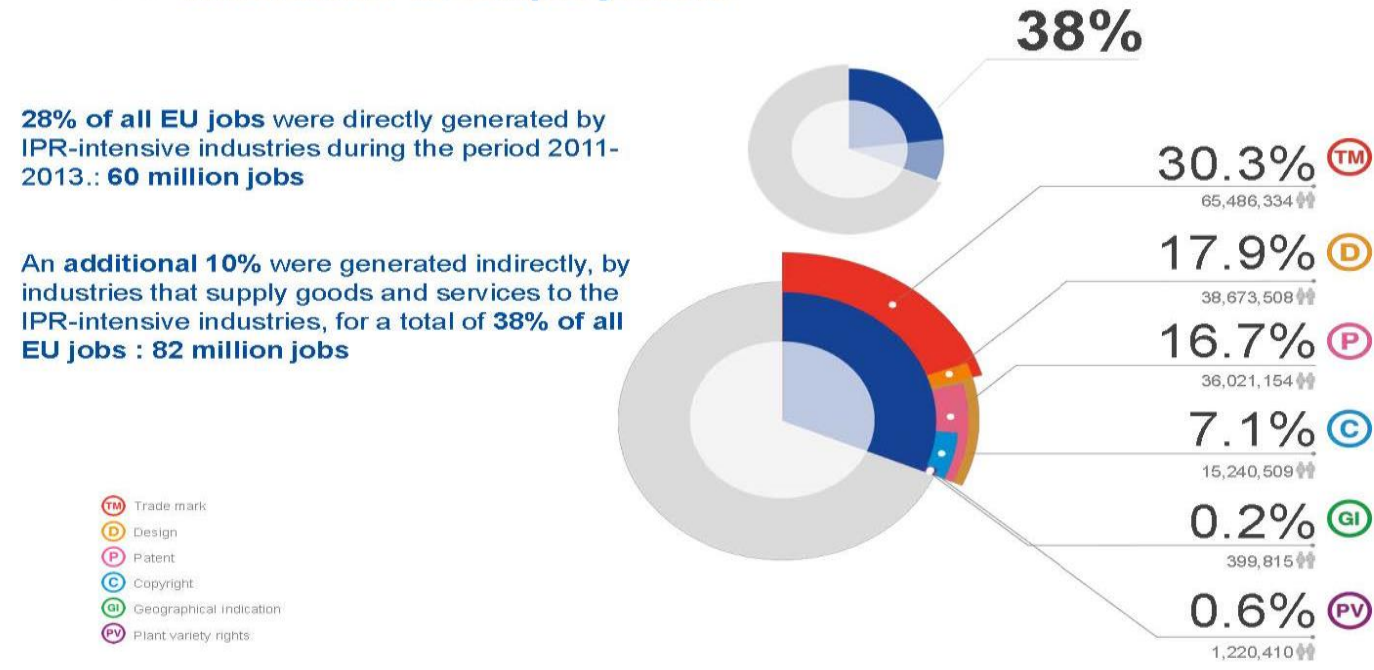

Fig. 6. IP-related employment in the EU in 2015 (EUIPO, Intellectual property rights intensive industries and economic performance in the EU) 

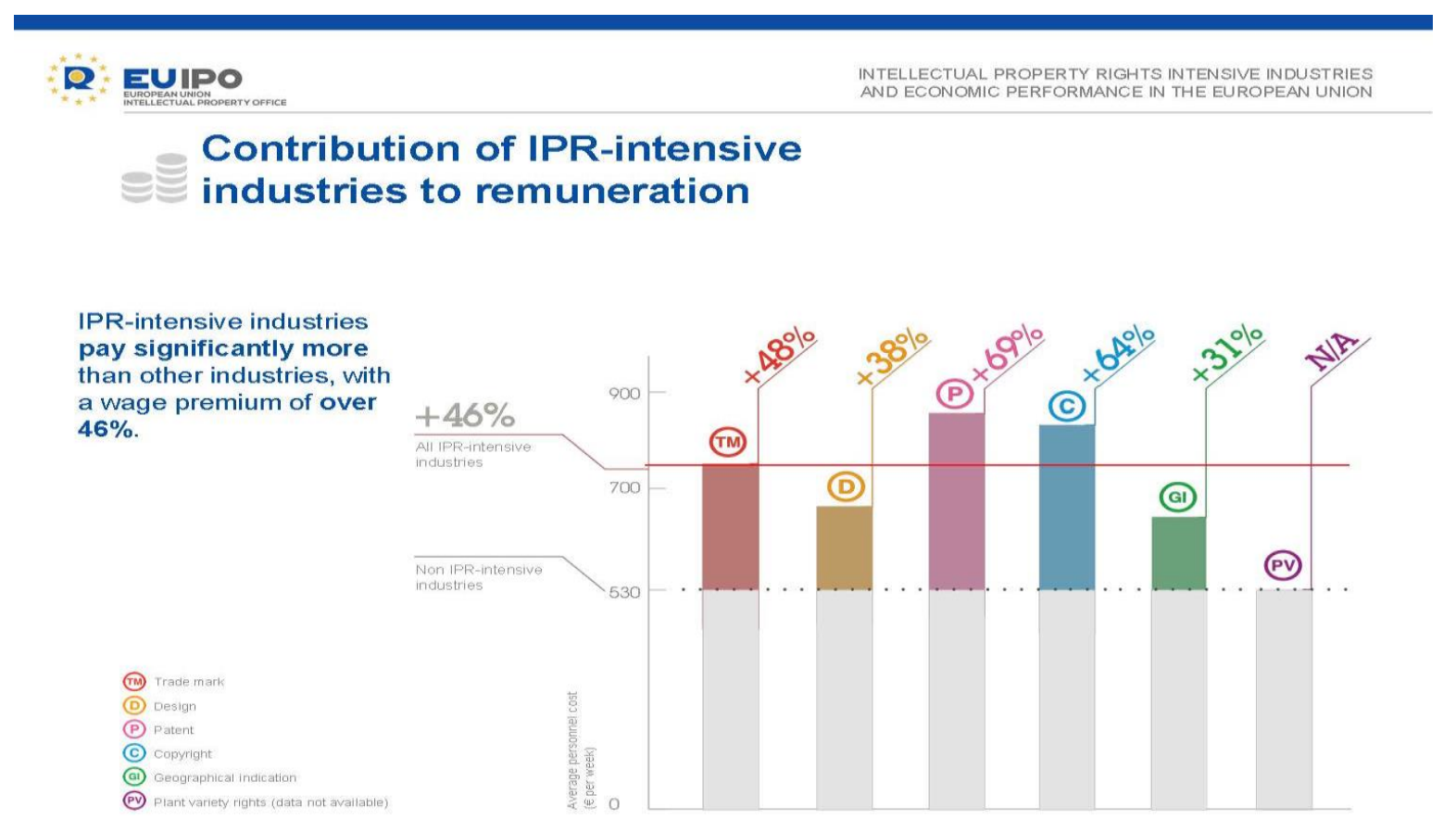

Fig. 7. IP-related employment in the EU in 2015 (EUIPO, Intellectual property rights intensive industries and economic performance in the EU)

\section{$5 \quad$ Who Needs IP Literacy Training?}

A recent survey of UK student knowledge jointly run by the National Union of Students (NUS), the Intellectual Property Office (IPO) and the International Property Awareness Network (IPAN) [6, p.8] found that only $40 \%$ of students considered their current awareness of IP to be enough to support them in their future careers. The report also states, "Overwhelmingly, students felt that a knowledge of IP is important to both their education and their future career. There is evidence that IP teaching earlier in their education motivates greater interest among students at FE/HE level...Students feel it was important to know about IP to ensure everyone receives recognition for their work and ideas, but they do not perceive a strong link between IP and commercial success.... Many students want to see improvements to IP teaching. In particular, they want the teaching of IP issues to be more closely-related to their course discipline. They also called for coverage of IP to extend beyond plagiarism" (original emphasis retained).

Villasenor's [7, p.1] survey of engineering students at UCLA demonstrated a similar lack of awareness and points out the consequences of this ignorance. In an informal survey of 60 engineering students asking about the different forms of IP, he found that $21 \%$ "did not know enough to answer the question "what is a patent?'" For the other types of IP, he found that $61 \%$ could not define a trade secret, $32 \%$ could not define copyright and $51 \%$ could not define a trademark. He points out that if students are unable to identify IP, how can they be relied upon to "promptly report and fully disclose their patentable inventions" as required by funding agencies funding the research they work on. 
Pitkethly [8, p.163] wrote that the "intellectual property system has several objectives but the most important, especially in the case of the patent system, is providing an incentive for innovation. To provide that potential innovators must be aware of it. The effectiveness of the system thus depends not just on what it provides but on what innovators perceive that it provides. An equally important issue though is whether innovators are sufficiently aware of the system to be able to use it effectively." Librarians are optimally placed to assist in raising awareness of IP.

Intellectual property rights (IPR) exist to encourage and promote the sharing of innovations and new technologies in the public domain while giving the inventor(s) protection for their inventions. To make this a win-win situation, it is critical that IP rights are taught alongside basic IL skills. As Pitkethly [8] wrote, awareness is needed, and not just awareness but a solid understanding of IP and the rights they confer.

6 The Benefits from a Greater Understanding of the Patenting Process and of Patents

Learning how the patent process is structured will help researchers to maximize and streamline their application process and to avoid inadvertently losing their rights to a patent. The following reasons underscore the need for greater awareness and understanding of IP/patents in the STEM and business disciplines. STEM librarians can introduce IP and patents when introducing resources available for research. Researchers and students need an understanding of how patents fit within the discipline's literature. The technical information contained in patents is often not found elsewhere. This technical information can be used to prevent research redundancy and direct funding to areas that need more research. It can also be used to strengthen research-funding applications by demonstrating a comprehensive search of all literature, to determine potential areas for further research and to use current and expired patents as building blocks for new technologies. MacMillan [9, p.157] introduced IPL into his training and concluded that "introducing patent literature to upper-level science students has enhanced their information literacy skills. Students participating in these sessions have a greater understanding of the different types of primary information in their subject areas and the place patents have in their field of study. These students are also more aware of the economic, legal and social issues surrounding the use of information or technologies and the importance of stay abreast of developments in their field."

Business librarians can incorporate IP when introducing business resources to management and entrepreneurship classes. Just as inventors need to know about IP, future business managers and entrepreneurs need to understand how to identify and protect a company's IP. Understanding the need to do a thorough patent search can prevent inadvertent infringement and potential lawsuits. Current patents can be used to identify new, emerging or core technologies. Recent patents can provide indicators of future trends and industries where research and development (R\&D) funding should be directed. This in turn helps business managers and entrepreneurs to discover competitors and potential partners or licensing partners. And most basic of all, understanding and awareness of IP 
allows an inventor or entrepreneur to effectively protect his or her IP by not disclosing it prematurely. Though not within the scope of this paper, it should be noted that Arts librarians can teach about IP for design patents.

For librarians in academic settings, there is an opportunity to work collaboratively with the funding, technology transfer and legal departments at the University as well as with faculty members, researchers and students engaged in innovation. IPL training provides an opportunity for librarians to learn new skills and demonstrate their relevance. Such skills development among librarians benefits the entire university as well as highlights the value libraries and librarians bring to the institution.

\section{A Six-Step Framework}

Step 1: Begin with an assessment of the target audience's knowledge of IPL. This allows the librarian to understand the current needs of the target audience and it also shows people what they do not know or know well. It is a useful way to attract their attention. There are two parts to a holistic IPL program. The theoretical part covers the patent process, while the applied part focuses on patent searching and analysis.

Step 2: Start the training by defining IP and its place in research and business. Provide a glossary of important terms used in the patent literature. Define what rights are given to a granted patent. Then outline the (general) patent process by asking and answering the following questions: What are the criteria (depending on where the patent will be filed)? What are general timelines and procedures? What is possible to do with the invention while waiting for a patent decision? What are the costs, protections afforded, geographic locations where the patent is enforced? When is it time to consult with legal experts?

Step 3: Discuss some of the common mistakes made by uninformed inventors, including premature disclosure, non-disclosure agreements (NDAs), claims overlaps, trying to patent an invention that is already patented, etc.

Step 4: In the Applied half, start with directions on how to read a patent. Identify the different sections of the patent and explain the purpose and importance of each section.

Step 5: Identify patent search resources. Provide information on the various patent office databases (national and international) and other free patent resources. If there is a subscribed patent database (e.g., Derwent World Patent Index, PatBase, etc.) available, discuss the benefits of using a free vs. a subscribed database.

Step 6: Provide details on how to effectively search for patents using patent record fields and classification schemes. It is useful to create exercises to provide handson practice in searching for patents and following patent citations to find additional information. Exercises can be on using keywords, classification systems, how to find the surrounding cited literature, how to determine what stage a patent is in, etc. Discuss what a "State of the Art" (SOTA) search is and when you should be doing a SOTA.

For more detailed and discipline-specific ideas, MacMillan [9], MacMillan and Thuna [10], and Zhang [11] all have written about IPL training in science disciplines or classes, with information on integrating IPL into a class assignment. 


\section{$8 \quad$ Librarian Training Options}

Librarians can learn about IP via the various training options available from the patent offices (WIPO, EPO, USPTO, national patent offices) and professional associations such as the Patent International User Group (PIUG). Many patent offices are working to increase awareness of IP rights with online training and outreach programs and some even have training materials geared for use in elementary/primary and secondary schools. Understanding the needs of the discipline, business or entrepreneur determines the level of the IPL training needed and allows this training to be adapted and inserted into specialized and general IL training programs. There are many opportunities for librarians to learn more about IP and in turn to translate this new knowledge into IPL training. A list of selected sites with training materials can be found in the Appendix.

\section{Conclusion}

A lack of awareness and understanding, few examples of how to start a program, and where to get appropriate training are key reasons that IPL is not more widespread and why IPL programs are not offered by librarians. While patents have been around for years, it is only with the advent of online databases that patents have become accessible to anyone with internet access. Online access is creating huge opportunities for librarians in all disciplines to learn new skills and gain new expertise. Prior to online patent databases, patents were seen as the sole responsibility of patent attorneys, IP specialists or technology transfer offices who had access to the patent offices and patent depository libraries. As IP in the form of patents is becoming exponentially more important in the research-tocommercialization process, more work on information literacy training about patents is needed. In providing definitions of IP literacy, placing the value of IP literacy in a larger context, looking at target audiences, proposing a framework for IP literacy and providing suggestions about the role that librarians can play in developing IP literacies beyond copyright, this paper opens the discussion of IPL as part of a librarian's IL training responsibility.

\section{References}

1. United States Patent and Trademark Office, https://www.uspto.gov/learningand-resources/general-faqs\#1242

2. World Intellectual Property Office, http://www.wipo.int/edocs/pubdocs/en/intproperty/450/wipo_pub_450.pdf

3. American Library Association, http://www.ala.org/acrl/standards/informationliteracycompetency\#ildef

4. United States Patent and Trademark Office: Intellectual property and the U.S. economy: 2016 update, https://www.uspto.gov/sites/default/files/documents/IPandtheUSEconomySep t2016.pdf

5. European Union Intellectual Property Office: Intellectual property rights intensive industries and economic performance in the EU, https://euipo.europa.eu/ohimportal/en/web/observatory/ip-contribution\#ipcontribution_1 
6. National Union of Students, the Intellectual Property Office and the International Property Awareness Network: Student attitudes towards intellectual property, http://ipaware.org/wpcontent/uploads/2016/10/20121012-IP-report.pdf (2016)

7. Villasenor, J.: Intellectual property awareness at universities: why ignorance is not bliss. https:/www.forbes.com/sites/johnvillasenor/2012/11/27/intellectualproperty-awareness-at-universities-why-ignorance-is-notbliss/\#3851363a13ce (2012).

8. Pitkethly, R.H.: Intellectual Property Awareness. International Journal of Technology Management 59 (3-4), 163 (2012)

9. MacMillan, D.: Patently obvious: The place for patents in information literacy in the sciences. Research Strategies, 20(3), 149-161 (2006)

10. MacMillan, D., Thuna, M.: Patents under the microscope. Reference Service Review 38 (3) (2010)

11. Zhang, L.: Developing a systematic patent search training program. The Journal of Academic Librarianship, 35(3), 260-266 (2009)

\section{Appendix: Selected Patent Training Resources}

Academy of the European Union Intellectual Property Office:

https://euipo.europa.eu/ohimportal/en/academy

EUIPO Educational Materials:

https://euipo.europa.eu/ohimportal/en/web/observatory/educational-materials

European Patent Office: https://www.epo.org/about-us/office/academy.html USPTO Webinars and IP E-learning Modules [available in the following languages: English, Spanish, French, Arabic, Russian]:

https://www.uspto.gov/learning-and-resources/global-intellectual-propertyacademy-gipa/uspto-webinars-and-ip-e-learning

WIPO Academy: http://www.wipo.int/academy/en/ 